\title{
Reliability assessment of deteriorating reinforced concrete beams
}

V. Sarveswaran, M. B. Roberts and J. A. Ward

\section{Coronelli, Politecnico di Milano}

I read the paper with great interest, in particular the application of the reliability theory to the structural effects of chloride corrosion. The most interesting issue in relation to my research work is the finding that within this probabilistic approach bond failure can be identified as the critical failure mode for a deteriorating beam. I have investigated this possibility from a deterministic point of view by finite-element analysis of corroded beams. ${ }^{1}$

A key parameter to determine bond failure is the residual bond strength of corroded bars. Sarveswaran et al. propose an equation to determine the force that can be generated in a bar, when delamination of the cover has taken place (Equation (10b) in the paper), introducing a factor $\alpha$ for loss of bond of outer layer bars.

I believe it would be interesting to clarify how this factor for bond loss was determined in this study: the possibility of bond failure depends on this parameter (and from the delaminated length). Many studies in the literature have shown bond deterioration of corroded bars experimentally. ${ }^{2}$ I believe that the quantitative evaluation of residual bond strength has not yet been achieved. One relationship has been proposed by Rodriguez et al., ${ }^{3}$ but the validity of this model is limited in my opinion to the anchorage of single bars, and not to groups of bars, as those in bridges shown in Fig. 4 in the paper. I would be interested to know the authors' opinion on this topic.

\section{Author's reply}

The authors wish to thank Dr Dario Coronelli for his consideration of our paper and we welcome the opportunity to clarify how the factor for the bond loss was determined.

The delamination of cover concrete and corrosion of shear links result in reduction of the bond strength of the main reinforcement which in turn results in the reduction of the load-carrying capacity. As there was insufficient knowledge available from which to calculate the loss of bond strength resulting from delamination of cover concrete, a number of scaled model tests were carried out by Professor P. E. Regan at the University of Westminster to determine delaminated bond strength. Similar tests were carried out by Professor Regan 12 years ago to determine a single bond value for delaminated cross-beams with 100\% shear links effective.

The main objective of the recent model testing was to determine an appropriate value of bond strength for assessment purposes where the cover concrete was delaminated. The tests aimed to confirm the bond strength to be used when there is delamination with fully effective shear link restraint (PCL's original test determined a value of $32 \%$ of the code value), and to determine delaminated bond strength when the shear links are no longer fully effective as a result of corrosion.

Scale models (40\%) of typical Midland Links cross-beam configurations with closely spaced bars as in Fig. 4 and typical arrangements of stirrups were tested to simulate the actual beam situation rather than less representative single-bar pullout tests. Many of the bars were instrumented with electrical resistance strain gauges at key locations. The beams were monitored throughout the load tests and the results were used in a back-analysis to determine bond values for the bar groups.

A number of model beams were tested with varying proportions of links modelled without their end anchorage to simulate severe corrosion. This modelled the reduced restraint of the shear links on the main bars as a result of the corrosion of shear links, which were known to have a major effect on the bond strength once delamination has occurred.

The results are shown in Table 1 . The $0 \cdot 3$ value compares favourably with the value of $0 \cdot 32$ of the code strength derived from the bond tests which was carried out 12 years ago. The model testing was successful in providing realistic bond values for main bars on delaminated cross-beams with significant

\begin{tabular}{|cc|}
\hline \% of shear link corrosion & $\begin{array}{c}\text { Proportion of code value for } \\
\text { ultimate bond stress }\end{array}$ \\
\hline 0 & 0.30 \\
Average of $50 \%$ and $75 \%$ & 0.25 \\
\hline & \\
\hline & \\
\hline
\end{tabular}


corrosion of links and they were used for the development of the new Midland Links Risk-based Repair Strategy. ${ }^{16}$

\section{REFERENCES}

1. Castellani A. and Coronelli D. FE analysis of RC beams with corroded reinforcement. Proceedings of the 8 th International Conference on Structural Faults and Repair, London, July, 1999.
2. Berra M., Castellani A. and Coronelli D. Bond in RC and corrosion of bars. Proceedings of the 7th International Conference on Structural Faults and Repair, Edinburgh, July, 1997, 349-357.

3. Rodriguez J., Ortega L. and Garcia A. M. Corrosion of reinforcing bars and service life of RC structures: corrosion and bond deterioration. Proceedings of an International Conference on Concrete across Borders, Odense, 1994. 